\title{
PhD Education Challenges - Doctoral Candidates' Perspectives
}

\author{
Krzysztof Nesterowicz, MPharm, PhD candidate,
} Doctoral School of Public Administration Sciences, National University of Public Service, Budapest, Hungary

Slobodan Radicev, PhD candidate,

Faculty of Technical Sciences, University of Novi Sad, Novi Sad, Serbia Seyed-Mohammad Fereshtehnejad, MD, MPH, MSc, PhD,

Department of neurobiology, care sciences and society (NVS),

Karolinska Institutet, Stockholm, Sweden

\section{John Peacock, PhD,}

University of Colorado Denver, Anschutz Medical Campus, Denver, USA

\section{András Nemeslaki, PhD, Professor}

Department of Finance and Accounting,

Budapest University of Technology and Economics, Budapest, Hungary

\begin{abstract}
Doctoral training was included in the Bologna system as the third cycle. The important consequence of this change is that the doctoral studies became more structured, and most universities now train doctors in a shorter time period than in the past, mostly in 3 to 4 years. The National Association of PhD students from Serbia (Doktoranti Srbije) conducted the same survey in the form of a questionnaire three years in a row (2010-2012). In 2010 the survey received 335 responses, in 2011 there were 557 responses and in 2012 there were 625 . The survey results showed that doctoral candidates recognise supervision as a key issue that need to be improved. Surveyed individuals emphasised the impact of the supervisor's engagement on the quality of their PhD projects. Supportiveness is the quality that $\mathrm{PhD}$ students value the most. This involves supervisors being encouraging, and aware that students' lives extend beyond the $\mathrm{PhD}$. Other key areas for improvement, according to Serbian $\mathrm{PhD}$ candidates, are financing and mobility, especially international mobility.
\end{abstract}

Keywords: $\mathrm{PhD}$ candidate, $\mathrm{PhD}$ education, doctoral training, supervision. 


\section{Introduction}

Over the past years, the concentration of knowledge creation and academic trend setting has become even more concentrated into the US, and some few Western European and Asian centres (Figure 1). This is not only due to the traditional brain-drain processes but also to a large extent to the technology development and more intensive ICT use [Nemeslaki, 2013].

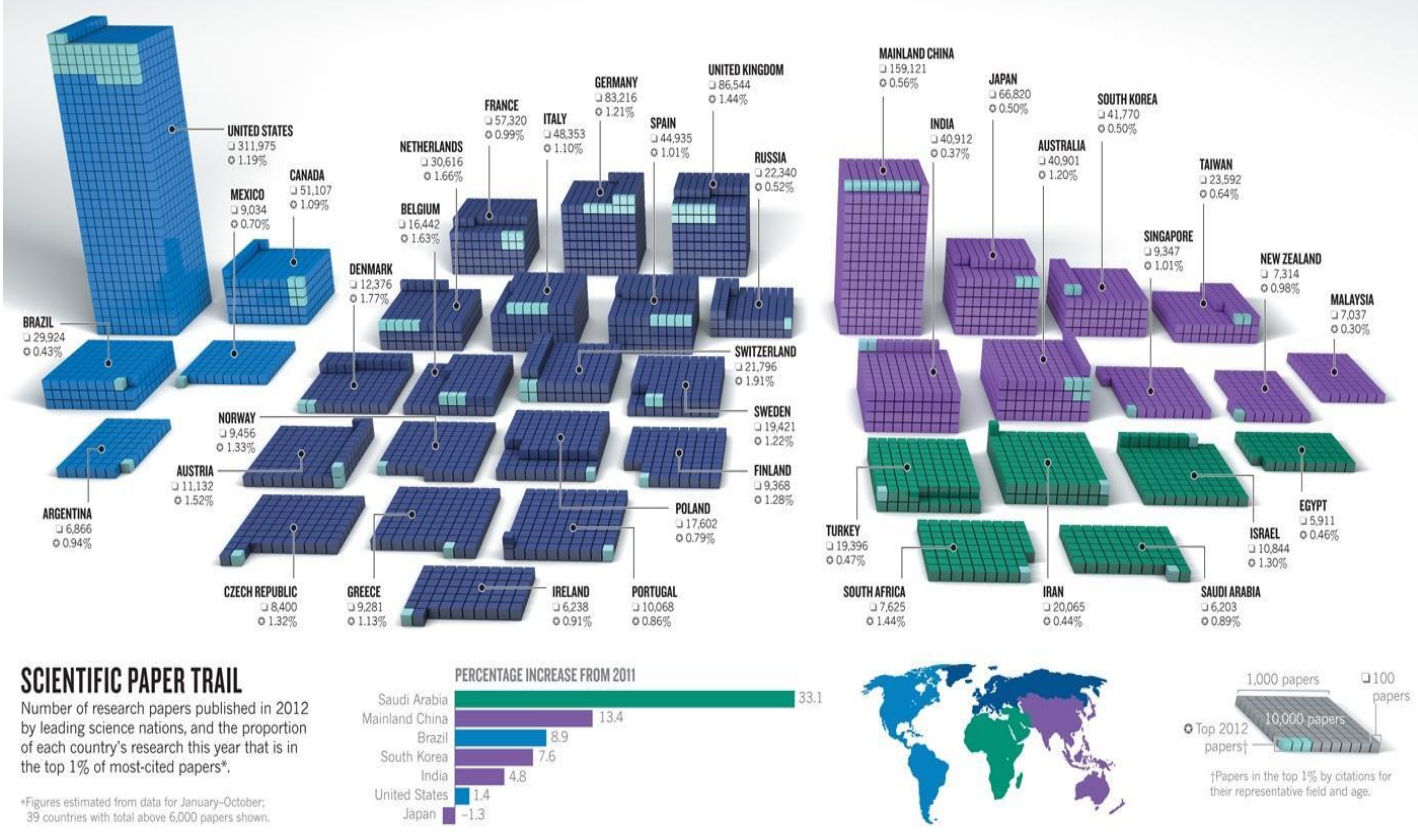

Figure 1. Number of research papers published in 2012 by leading science nations and the proportion of each country's research that year that is in the top $1 \%$ of most-cited papers [Hsu, 2013].

In Europe, we experience the impact of European Higher Education Area which enables thousands of students, academics and administrative personnel to gather experience, teach/research and study in different European educational institutions. $\mathrm{PhD}$ education has become a credit based, structured program; a part of the national accreditation systems; basically, the third tier of the Bologna-based educational pyramid [Nemeslaki, 2013].

Universities do research with companies and governments; $\mathrm{PhD}$ students quite often have full-time jobs while working on their dissertations; $\mathrm{R}+\mathrm{D}$ projects have become inherently complex involving many stakeholders for achieving success; and finally the financial pressure on $\mathrm{PhD}$ education remain ever relevant. Doctoral education is expensive and new models have to be invented to share these costs between tax payers, individuals, and businesses. Universities have become part of the knowledge industry of their respective countries, and have started to have much broader responsibilities 
than education. Doctoral programmes have to be aligned to these challenges [Nemeslaki, 2013].

Doctoral education is a wise societal investment with excellent payoffs in both the short and long term. This has been demonstrated by Finland. Responding to the economic depression of the early 1990's, the Government of Finland introduced harsh cut-and-save policies except for research and education where the public spending was increased [Aho, 2006]. Today, Finland tops the country competitiveness rankings ahead of countries such as the US, Germany, and Japan [von Hentaller et al., 2014].

With respect to central and south east Europe, a Global Round Table report from 2014 (Doctoral Education in Central- and South-East Europe. Follower or Leader? A Wake-Up Call) states that 'The region's doctoral schools need to develop their specific approaches to doctoral education by building on international best practices, adjusted to reflect their specific missions and scientific uniqueness, as well as their research capacity, infrastructure, management and involvement with non-academic partners (industry, commerce, museums, archives, charities and other civil society actors) [von Hentaller et al., 2014].'

\section{Doctoral training}

The current system in most higher education institutions in the Central Europe region prepares doctoral candidates to stay and work in academia. With the rapidly increasing number of doctoral programmes it is obvious that most of the current PhD students will not have a place to stay at a university or scientific institute. Unfortunately, most of them are not prepared for this: studies by various organisation show that more than $80 \%$ of doctoral candidates would like to stay at a university or at some scientific institute after defending their PhD thesis [Doktoranti Srbije, 2013].

Doctoral candidates in the region need to be offered the training that will provide them skills required to work in a non-academic environment [European Commission, 2011]. Together with improvement of training for doctoral candidates there is a need to improve, or to develop, training for supervisors responsible for doctoral training [Communiqué, 2012].

The League of European Research Universities (LERU) describes the purpose of doctoral education as to train 'creative, critical, autonomous intellectual risk takers' [League of European Research Universities, 2010]. LERU states that PhD's must be encouraged to be entrepreneurial in developing new ideas, identifying new opportunities and seeking new ways of working in society. One should also see research training as developing a wide range of skills that will be of value in driving innovation [von Hentaller et al., 2014]. This includes both domain-specific and domain-general skills, that meaning domain-general skills such as time management, teamwork, 
leadership and self-motivation (relevant to a great many occupations), and domain-specific skills relevant only to a certain job [Wherry, Schor, 2015].

The European Commission (EC) has developed seven Principles of Innovative Doctoral Training [European Commission, 2011]. These principles are: research excellence, an attractive institutional environment, offering interdisciplinary research options, giving exposure to industry and other relevant employment sectors, enabling international networking, providing transferable skills training and maintaining good quality assurance processes. The EC's Horizon 2020 Programme will be seeking research training providers who follow these principles [von Hentaller et al., 2014].

Influenced by the ten Salzburg principles, universities in Europe have increased their effort to make targeted investments in the personal and professional development in the next generation of researchers [Smith, 2005; Byrne, Jørgensen, Loukkola, 2013]. For over a decade, European universities have been on the way to dramatically changing doctoral education [Crosier et al., 2010]. Doctoral schools and/or similar university units dedicated to tailored support of doctoral candidates and supervisors are considered as valuable vehicles for changing the mind-sets of governance structures related to doctoral education [von Hentaller et al., 2014].

\section{Doctoral candidates' perspective}

Only a decade ago doctoral candidates' goals in most countries were clear: a job in academia. Since then several major changes have occurred to transform PhD candidates' perspectives. The first big step was the inclusion of doctoral training in the Bologna system as a third cycle [Ministerial Conference, 2005]. The important consequence of this change is that the doctoral studies became more structured, and the time most to complete a PhD became shorter than in the past.

If we look at some of the countries of South-Eastern Europe, such as Serbia and Croatia, where national associations of doctoral candidates have conducted surveys on the quality of doctoral studies (Znanstveni novaci, Sveučilišta u Zagrebu, Analiza upitnika, Sastanak sa znanstvenim novacima Sveučilišta u Zagrebu, FER, 15. studenoga 2007 \& Doktoranti Srbije Anketa) we can see that, in addition to the above mentioned problems that are typical for the whole of Europe, there is a significant issue with supervisors [Doktoranti Srbije, 2013].

Starting at the end of 2013, a project to restructure doctoral studies, RODOS (Restructuring of doctoral studies in Serbia), that aimed to reorganise doctoral studies in line with the Bologna Process and Salzburg Principles, was begun. The programme placed emphasis on the quality of research and integrative processes involving universities, institutes and industry, and resulting in the establishment of doctoral schools [RODOS, 2013]. 
Prior to this program, the National Association of $\mathrm{PhD}$ students from Serbia (Doktoranti Srbije) conducted multiple surveys (2010, 2011, and 2012) which showed that doctoral candidates recognise supervision as a key issue that need to be improved. Other key areas for improvement according to Serbian $\mathrm{PhD}$ candidates are financing and mobility, especially international mobility. The problem of quality of doctoral studies in Serbia is not only recognised by doctoral candidates but also by government institutions and the EC. In this paper we report the results of these surveys.

\section{Methods}

\section{Data Collection}

The National Association of PhD Students from Serbia conducted an annual survey on the quality of $\mathrm{PhD}$ studies in Serbia. The surveys were distributed among the $\mathrm{PhD}$ candidate population in Serbia (approximately 10,000 people). The survey was supported by Ministry of Education, Science and Technological Development of the Republic of Serbia. In 2010 the survey reached 335 responds, in 2011 there were 557 responds and in 2012: 625, respectively. The vast majority of $\mathrm{PhD}$ candidates who responded to the survey came from four biggest state universities: Belgrade, Novi Sad, Nis and Kragujevac. These four universities have over $90 \%$ of all $\mathrm{PhD}$ candidates in the country.

\section{Questionnaire}

The survey was in the form of a questionnaire that consisted of between 27 and 54 questions depending on the year. The majority of questions were closed questions from which we could get quantitative data. The survey had also some open questions which confirmed and validated the results collected from closed questions. Key questions about the quality of $\mathrm{PhD}$ studies and main issues were always the same each year, so it was possible to compare data among the years.

\section{Statistical Analysis}

In order to describe numeric and categorical variables, we used mean [standard deviation (SD)] and frequency percentages, respectively. For the questions on students' attitude, we assessed floor and ceiling effects by counting the number and percentage of respondents receiving the minimum and maximum scores in each item, respectively. The Cronbach's alpha coefficient was calculated to assess the internal consistency and reliability of the attitude questionnaire. For univariate analysis, Pearson chi-square, independent samples $\mathrm{t}$ test, and Mann-Whitney $\mathrm{u}$ test were employed to compare different characteristics between the two groups of students, with or without publication, wherever appropriate. Moreover, we applied multivariate 
ordinal regression model to assess the factors resulting in students' negative attitude towards quality of teaching (low, medium, high) considering it as an ordinal dependent variable in the model. Corresponding odds' ratios (ORs) and their $95 \%$ confidence intervals (CIs) were calculated for each independent variable in the model.

All statistical analyses have been performed using the IBM SPSS Statistics for Windows, version 23 [IBM Corp., 2016]. A p-value of $<0.05$ has been considered to show statistically significant differences or associations.

\section{Results}

\section{Descriptive report}

A total number of 447 doctoral students participated in this survey. More than half of them $(n=257,57.5 \%)$ were in the $3^{\text {rd }}$ year of their education and $152(34.0 \%)$ students had scholarships. Table 1 describes some baseline characteristics and the distribution of the answers to the questionnaire. Among all doctoral students, 297 (66.4\%) had at least one published manuscript in a scientific journal. Results for the investigation of the factors associated with successful publication in doctoral students are summarised in Table 2.

\section{Reliability of the study questionnaire}

Over the entire list of questions, only $3.99 \%$ of responses were missing. There were medium floor effects (range: $4.3 \%-54.6 \%$, mean: $34.7 \%$ ) and minimal ceiling effects (range: $4.3 \%-29.8 \%$, mean: $11.7 \%$ ) in the answers to different either attitude-related and ranking items. The Cronbach's alpha coefficient was calculated as 0.514 (95\% CI: $0.437-0.585)$ and 0.873 (95\% CI: 0.854-0.890) for the sections on students' attitude about doctoral education and the priority ranking items on their opinion to improve the quality of doctoral education, respectively.

\section{Quality of teaching}

The mean number of ECTS credits in participated doctoral students was $96.8(\mathrm{SD}=52.1)$. As described in Table 1, near to quarter of the students $(n=102,22.8 \%)$ thought that ECTS credits system was not adequate, while only $132(29.5 \%)$ of them were satisfied by the quality of teaching during their doctoral education. Results from the multivariate regression model in Table 3 demonstrated that fewer meetings $[\mathrm{OR}=0.86$ (95\% CI 0.74-1.00)] and weaker cooperation with supervisors $[\mathrm{OR}=0.77$ (95\% CI 0.62-0.97)] are both risk factors for lower quality of teaching in students' opinion. On the other hand, those with higher number of ECTS credits were more likely to qualify teaching quality as high [OR=1.01, (95\% CI 1.00-1.01)]. 


\section{Quality of supervision}

The majority of the students $(n=391,87.5 \%)$ believed that they had a dedicated supervisor. While $74(18.9 \%)$ students met their supervisors every day, a quarter of them $(n=101,25.8 \%)$ had less than once per month meetings. Supervisors' participation in doctoral dissertation was ranked to be optimal or sufficient by $136(34.8 \%)$ and 159 (40.7\%) students, respectively. The majority of the students answered that their cooperation with their supervisors was either excellent $(n=180,46.0 \%)$ or very good $(n=91,23.3 \%)$.

\section{Publication of research manuscripts}

Data in Table 2 shows that corresponding academic centres more frequently employed doctoral students who had published manuscripts $(56.6 \%$ vs. $30.0 \%$, p 0.001$)$. Having scholarship was more common among students with publication $(37.7 \%$ vs. $26.7 \%, \mathrm{p}=0.020)$. Moreover, students who have succeeded to publish scientific papers had more ECTS credits [109.4 $(\mathrm{SD}=52.4)$ vs. $74.2 \quad(\mathrm{SD}=43.5), \mathrm{p}<0.001]$, more likely had dedicated supervisors $(92.6 \%$ vs. $77.3 \%, \mathrm{p}<0.001)$ and were more satisfied with their supports for publishing papers $(\mathrm{p}=0.025)$.

\section{Improvement of the quality of doctoral education}

Figure 1 illustrates doctoral students' attitudes towards various parameters to the improve quality of doctoral education. 'Relationship with supervisor', 'increase of funding' and the 'possibilities to study abroad' were more commonly ranked as the most important factor to improve quality of doctoral education.

Table 1. Baseline characteristics and distribution of the answers to the questionnaire in doctoral students.

\begin{tabular}{|l|l|}
\hline Variables & Value \\
\hline Year of education & \\
Beginning & $20(4.5)$ \\
$1^{\text {st }}$ & $66(14.8)$ \\
$2^{\text {nd }}$ & $104(23.3)$ \\
$3^{\text {rd }}$ & $257(57.5)$ \\
\hline Having scholarship & $152(34.0 \%)$ \\
\hline Being employed by the academic centre & $213(47.7 \%)$ \\
\hline Number of ECTS credits & $96.8(52.1)$ \\
Mean (SD) & \\
\hline Adequacy of the ECTS credits system & $19(4.3)$ \\
Very good & $96(21.5)$ \\
Good & $131(29.3)$ \\
Do not know & $99(22.1)$ \\
Not good & $102(22.8)$ \\
Not adequate & $55(12.3)$ \\
\hline Quality of teaching & Very good
\end{tabular}




\begin{tabular}{|c|c|}
\hline $\begin{array}{l}\text { Good } \\
\text { Do not know } \\
\text { Not good } \\
\text { Not adequate }\end{array}$ & $\begin{array}{l}77(17.2) \\
148(33.1) \\
91(20.4) \\
76(17.0) \\
\end{array}$ \\
\hline Dedicated supervisor & $391(87.5)$ \\
\hline $\begin{array}{l}\text { Meeting with supervisor } \\
\text { Every day } \\
\text { 2-3 times a week } \\
\text { Once a week } \\
\text { 2-3 times per month } \\
\text { Once a month } \\
\text { Less than once per month }\end{array}$ & $\begin{array}{l}74(18.9) \\
69(17.6) \\
51(13.0) \\
46(11.8) \\
50(12.8) \\
101(25.8)\end{array}$ \\
\hline $\begin{array}{l}\text { Support from supervisor for publishing papers } \\
\text { Excellent } \\
\text { Very good } \\
\text { Good } \\
\text { Satisfactory } \\
\text { Unsatisfactory } \\
\end{array}$ & $\begin{array}{l}208(53.2) \\
74(18.9) \\
50(12.8) \\
30(7.7) \\
29(7.4)\end{array}$ \\
\hline $\begin{array}{l}\text { Cooperation with supervisor } \\
\text { Excellent } \\
\text { Very good } \\
\text { Good } \\
\text { Satisfactory } \\
\text { Unsatisfactory }\end{array}$ & $\begin{array}{l}180(46.0) \\
91(23.3) \\
62(15.9) \\
41(10.5) \\
17(4.3) \\
\end{array}$ \\
\hline $\begin{array}{l}\text { Participation of supervisor in dissertation } \\
\text { Optimal } \\
\text { Sufficient } \\
\text { Insufficient } \\
\text { Not at all } \\
\end{array}$ & $\begin{array}{l}136(34.8) \\
159(40.7) \\
70(17.9) \\
26(6.6) \\
\end{array}$ \\
\hline $\begin{array}{l}\text { Necessity of publication requirement for doctoral defense } \\
\text { Very good } \\
\text { Good } \\
\text { Do not know } \\
\text { Not good } \\
\text { Not adequate }\end{array}$ & $\begin{array}{l}63(14.1) \\
67(15.0) \\
119(26.6) \\
65(14.5) \\
133(29.8)\end{array}$ \\
\hline Having published papers & $297(66.4 \%)$ \\
\hline
\end{tabular}

Table 2. Factors associated with publication of research manuscripts during doctoral studies [data are presented as number (percentage) unless otherwise specified].

\begin{tabular}{|l|l|l|l|}
\hline Factor & $\begin{array}{l}\text { With } \\
\text { Publication } \\
(\mathbf{n = 2 9 7})\end{array}$ & $\begin{array}{l}\text { Without } \\
\text { Publication } \\
(\mathbf{n = 1 5 0})\end{array}$ & $\boldsymbol{p}$-value \\
\hline Having scholarship & $112(37.7 \%)$ & $40(26.7 \%)$ & $\mathbf{0 . 0 2 0}$ \\
\hline $\begin{array}{l}\text { Being employed by the academic } \\
\text { centre }\end{array}$ & $168(56.6 \%)$ & $45(30.0 \%)$ & $<\mathbf{0 . 0 0 1 *}$ \\
\hline $\begin{array}{l}\text { Number of ECTS credits } \\
\text { Mean (SD) }\end{array}$ & $109.4(52.4)$ & $74.2(43.5)$ & $<\mathbf{0 . 0 0 1}^{* *}$ \\
\hline Dedicated supervisor & $275(92.6 \%)$ & $116(77.3 \%)$ & $<\mathbf{0 . 0 0 1 *}$ \\
\hline Meeting with supervisor & & & $0.194^{* * *}$ \\
\hline
\end{tabular}




\begin{tabular}{|c|c|c|c|}
\hline $\begin{array}{l}\text { Every day } \\
2-3 \text { times a week } \\
\text { Once a week } \\
2-3 \text { times per month } \\
\text { Once a month } \\
\text { Less than once per month }\end{array}$ & $\begin{array}{l}57(20.7 \%) \\
50(18.2 \%) \\
31(11.3 \%) \\
33(12.0 \%) \\
38(13.8 \%) \\
66(24.0 \%)\end{array}$ & $\begin{array}{l}17(14.7 \%) \\
19(16.4 \%) \\
20(17.2 \%) \\
13(11.2 \%) \\
12(10.3 \%) \\
35(30.2 \%)\end{array}$ & \\
\hline $\begin{array}{lll}\text { Support from supervisor } & \text { for } \\
\text { publishing papers } & & \\
\text { Excellent } & & \\
\text { Very good } & \\
\text { Good } & \\
\text { Satisfactory } & \\
\text { Unsatisfactory } & & \\
\end{array}$ & $\begin{array}{l}155(56.6 \%) \\
51(18.6 \%) \\
32(11.7 \%) \\
18(6.6 \%) \\
18(6.6 \%) \\
\end{array}$ & $\begin{array}{l}53(45.3 \%) \\
23(19.7 \%) \\
18(15.4 \%) \\
12(10.3 \%) \\
11(9.4 \%)\end{array}$ & $0.025^{* * * *}$ \\
\hline $\begin{array}{l}\text { Cooperation with supervisor } \\
\text { Excellent } \\
\text { Very good } \\
\text { Good } \\
\text { Satisfactory } \\
\text { Unsatisfactory }\end{array}$ & $\begin{array}{l}126(46.0 \%) \\
91(23.3 \%) \\
62(15.9 \%) \\
41(10.5 \%) \\
17(4.3 \%)\end{array}$ & $\begin{array}{l}54(46.2 \%) \\
24(20.5 \%) \\
24(20.5 \%) \\
8(6.8 \%) \\
7(6.0 \%)\end{array}$ & $0.875^{* * *}$ \\
\hline
\end{tabular}

Statistical significant differences ( $p$-value $<0.05$ ) are bolded.

$S D$ : standard deviation

* Pearson chi square, ** Independent samples $t$ test, *** Mann-Whitney u test

Table 3. Multivariate ordinal regression model to assess the factors resulting in students' negative attitude towards quality of teaching during doctoral studies.

\begin{tabular}{|l|l|l|l|l|}
\hline Parameter & $\mathbf{B}$ & SE & $\boldsymbol{p}$-value & OR (95\% CI) \\
\hline $\begin{array}{l}\text { Fewer meetings with } \\
\text { supervisor }\end{array}$ & -0.15 & 0.08 & 0.053 & $0.86(0.74-1.00)$ \\
\hline $\begin{array}{l}\text { Weaker cooperation with } \\
\text { supervisor }\end{array}$ & -0.26 & 0.11 & $\mathbf{0 . 0 2 3}$ & $0.77(0.62-0.97)$ \\
\hline Scholarship & -0.54 & 0.26 & $\mathbf{0 . 0 3 7}$ & $0.58(0.35-0.97)$ \\
\hline $\begin{array}{l}\text { Employment } \\
\text { academia }\end{array}$ & 0.34 & 0.28 & 0.224 & $1.40(0.82-2.40)$ \\
\hline Having published papers & -0.46 & 0.28 & 0.100 & $0.63(0.37-1.09)$ \\
\hline Number of ECTS credits & 0.01 & 0.03 & $\mathbf{0 . 0 4 3}$ & $1.01(1.00-1.01)$ \\
\hline
\end{tabular}

Dependent variable in the regression model is quality of teaching coded as: 1 (low), 2 (medium), 3 (high).

Statistical significant associations (p-value $\leq 0.05)$ are bolded.

SE: standard error, OR: Odds' ratio, CI: confidence interval 


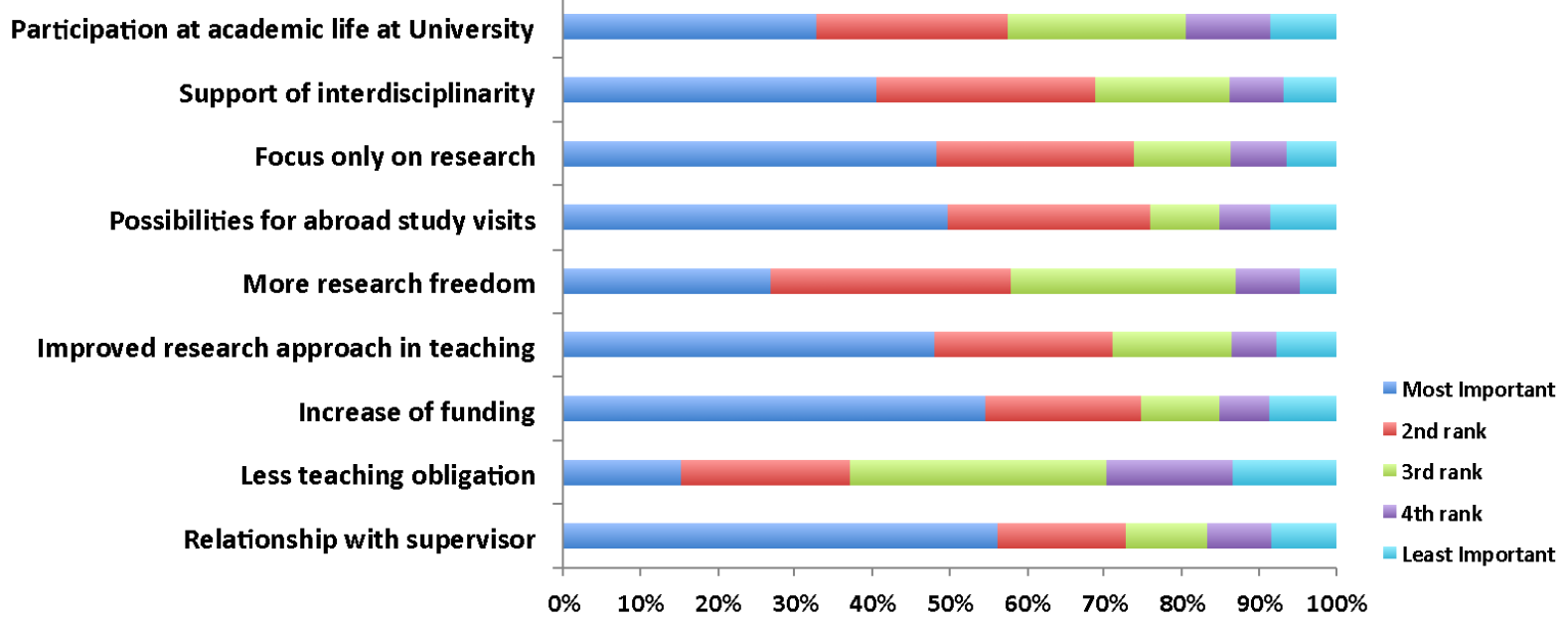

Figure 1. Students' attitude towards priority of the parameters to improve quality of doctoral education.

\section{Discussion}

In order to get a clearer picture of the situation of doctoral training in Central- and South-East Europe, we need to notice that most of them were communist countries that started with the transition to a free market economy in the early 1990s. The transition in all countries was painful for many citizens and many government budgets prioritised social benefits instead of investment in the future and in science. Today we have situation that all South-East European countries are on the bottom of the list of European countries in terms of research spending as a proportion of GDP [von Hentaller et al., 2014].

The history in these countries has shaped the current situation these countries find themselves in. Cultural attitudes towards and within academia are influenced by past structures which can be slow to change. Early career researchers may not have the same opportunities in these countries as they might in countries in Western Europe or North America with greater scientific output. Researchers may not also receive similar standards of training and support. By considering the concerns of doctoral candidates in the region, we may be able to take significant steps to improving the prospects for these researchers.

In addition to simply increasing research spending, more simple improvements in supervision can be implemented. Surveyed $\mathrm{PhD}$ candidates emphasised the impact of proper supervisor's engagement on the quality of their $\mathrm{PhD}$ projects. Supportiveness is the quality that $\mathrm{PhD}$ students value the most. This involves supervisors being encouraging, mentoring and aware that students' lives extend beyond the $\mathrm{PhD}$ [Janssen, 2004]. Although supervision was regarded as good in the surveys, the figures could still be greatly 
improved. Well-structured training programmes for supervisors could help this.

The other important issue identified by survey respondents was opportunities to study abroad, or for international collaboration. Building on relations with institutions in other countries, and building new research partnerships should allow more opportunities for Serbian doctoral candidates.

\section{Conclusion}

There is a trend in Europe to organise doctoral education within the framework of doctoral schools. This underlines the institutional responsibility of degree awarding institutions. Quality assurance and creating critical mass of research are key issues related to doctoral schools both of which increase efficiency of the system and raise visibility. The roles of doctoral candidates as early stage researchers become redefined and, furthermore, the value of their doctoral experiences can be increased.

In less developed areas such as Central-East Europe, investment in higher education is needed, in particular from the public sector. In the area of doctoral education, the establishment of doctoral schools is a response to this need as more attention is given to accountability and quality enhancement. Central-East European universities are lagging behind in this regard compared to other regions of Europe. This is partly because of less favourable legislation. However, various measures can be taken to improve the experiences of early career researchers, which may help to reduce the risk of increasing the gap between Central-East Europe and other parts of the European Higher Education and Research Area [von Hentaller et al., 2014].

\section{References:}

1. Aho E.: Creating an Innovative Europe. Keynote address at the European Regional Economic Forum. 14 June 2006, Nova Gorica, Slovenia.

2. Byrne J., Jørgensen T., Loukkola T.: Quality Assurance in Doctoral Education - results of the ARDE project. EUA Publication, 2013.

3. Communiqué: High Level Dialogue on Excellence in European Doctoral

Training. Aarhus, Denmark, September $20^{\text {th }}-21^{\text {st }} 2012$ : http://www.au.dk/fileadmin/www.au.dk/Internationalt_Center/Comm unique_High_Level_Dialogue.pdf [17.06.2014].

4. Crosier D., Purser L., Smidt H.: Trends V: Universities shaping the European Higher Education Area. EUA report, May 2010.

5. Doktoranti Srbije: Survey of the Association of Doctoral Candidates and Young Researchers of Serbia, 2013: http://doktoranti.org.rs/aktivnosti/anketa/ [17.06.2014.]. 
6. European Commission: European Commission Directorate-General for Research \& Innovation: Principles for Innovative Doctoral Training. 2011:

https://euraxess.ec.europa.eu/sites/default/files/policy_library/principl es_for_innovative_doctoral_training.pdf [24.01.2019].

7. Hsu S.: Scientific publications by country. Pessimism of the Intellect, Optimism of the Will. 2013: http://infoproc.blogspot.hu/2013/01/scientific-publications-bycountry.html [31.03.2014].

8. IBM Corp., Armonk, N.Y., USA. 2016.

9. Janssen A.: Perspectives on quality supervision. University of Otago, New Zealand. 2004: https://www.otago.ac.nz/graduateresearch/study/phddoctoral/programme/otago403801.html [24.01.2019].

10. League of European Research Universities: Doctoral degrees beyond 2010: Training talented researchers for society. March 2010:

11. Ministerial Conference: Communiqué of the Conference of European Ministers Responsible for Higher Education: The European Higher Education Area - Achieving the Goals. Bergen, $19^{\text {th }}-20^{\text {th }}$ May, 2005: http://www.ehea.info/media.ehea.info/file/2005_Bergen/52/0/2005_B ergen_Communique_english_580520.pdf [24.01.2019].

12. Nemeslaki A.: The Role of Ph.D. Consortiums in the Internationalization of Ph.D. Education. PiNet Conference, Budapest, Hungary, November $13^{\text {th }}-15^{\text {th }} 2013$.

13. RODOS: Restructuring of doctoral studies in Serbia. 2013: http://projects.tempus.ac.rs/en/project/856 [26.07.2018].

14. Smith J.: EUA Final Report, Doctoral Programmes for the European Knowledge Society. 2005.

15. von Hentaller U.F., Fayl G., Bogle D., Bazsa G., Bilik I., Breskvar K., Djurovic M., Grga I., Gönen E., Hansen N., Hill C.T., Hoedl E., Ilchev I., Jagic K., Koletnik M., Kosmider T., Kovačević M., Kovács G., Kroo N., Levendovszky J., Masát A., Matulic J., Mesko D., Mihaljevic S., Németh-Zámbori É., Posfai M., Radicev S., Racz K., Routti J., Slaus I., Szolgay P., Zinner L.: Doctoral Education in Central- and South-East Europe: Follower or Leader? A Weak-Up Call (2013). The Global Round Table Main Event, November 2013: https://ssrn.com/abstract=2405663 [24.01.2019].

16. Wherry F.F., Schor J.: The SAGE Encyclopedia of Economics and Society. First Edition. SAGE Publications. 2015. 